\title{
Processo de competência informacional em jogo
}

\author{
Leila Fernandes dos Santos \\ Universidade de Brasília, Centro de Desenvolvimento Tecnológico, Brasília, DF, Brasil \\ leilabiblioteca@gmail.com \\ Tânia Cristina Cruz \\ Universidade de Brasília, Centro de Desenvolvimento Tecnológico, Brasília, DF, Brasil \\ taniacristina75@gmail.com \\ Sônia Marises Salles Carvalho \\ Universidade de Brasília, Centro de Desenvolvimento Tecnológico, Brasília, DF, Brasil \\ smarises1960@gmail.com
}

DOI: https://doi.org/10.26512/rici.v13.n2.2020.31367

Recebido/Recibido/Received: 2019-12-20

Aceitado/Aceptado/Accepted: 2020-05-06

Resumo: O presente trabalho apresenta uma proposta que busca integrar as áreas de Biblioteconomia, Tecnologia e Inovação, no sentido de trazer uma reflexão sobre o grande potencial de inovação existente nas universidades, e vislumbra uma abordagem sobre disseminação da informação como prática pedagógica para que o processo de formação acadêmica possa proporcionar um melhor aproveitamento das tecnologias e ações e aproximá-las das práticas de ensino, pesquisa e extensão, no que se refere $a$ estabelecer e criar oportunidades aos discentes na construção de conexões estratégias das práticas com o mercado de trabalho. Este trabalho é uma pesquisa qualitativa com abordagem hipotético-dedutiva por partirmos da premissa geral do papel e da função de uma biblioteca universitária e pública. Quanto aos meios de investigação para este trabalho, foram utilizadas as análises bibliográficas e documentais; quanto aos fins, esta pesquisa caracteriza-se como descritiva, uma vez que se pretende descrever e analisar os fatores determinantes para a disseminação das informações sobre inovação e tecnologia em ambiente acadêmico. Por meio de um serviço de referência voltado para processos de inovação e com o uso de um aplicativo mobile, busca-se a formação de habilidades para a competência em informação com relação a como devem ser efetuados os depósitos de patentes, os registros de marcas, os depósitos de direitos autorais e os registros de programas de computador, além de demonstrar a relevância da participação/colaboração das bibliotecas universitárias nos Planos de Desenvolvimento Institucionais. O presente estudo corrobora com a importância de se pensar e prospectar novas práticas pedagógicas que proporcionem um processo de vivência que aproxime a experiência acadêmica da realidade antes mesmo da formação do aluno e o auxilie na compreensão das diferentes formas de inovação que pode haver no exercício profissional almejado.

Palavras-chave: sistemas de informação. competência em informação. processo de disseminação da informação. inovação tecnológica. videogame.

\section{Information Literacy in videogames}

Abstract: This paper presents a proposal that seeks to integrate the areas of librarianship, information technology and innovation to bring forth a reflection on the great potential for innovation existing in universities. It envisions an approach on the dissemination of information as an educational tool so that the process of academic training can provide a better use of technologies and actions and bring them closer to teaching, research and extension practices, with regard to establishing and creating opportunities for students to build strategic connections between academic practices with the labor 
market. It is a qualitative study with a hypothetical-deductive approach, based on the general premise of the role and function of a public, university library. Bibliographic and document analyses were used as means of investigation for this work. This research is characterized as descriptive since it is intended to describe and analyze the determining factors for the dissemination of information on innovation and technology in the academic environment. Through a reference service focused on innovation processes and by means of a mobile application, it seeks to build skills for competence in information regarding how patent applications, trademark registrations, copyright applications and software registrations are carried out and demonstrate the relevance of the participation and collaboration of university libraries in institutional development plans. We aim to highlight the importance of developing new educational practices that provide a process of gaining experience, which brings academic research closer to reality even before a student has graduated and helps them to understand the different forms of innovation that may exist in the desired professional field.

Keywords: information systems. information dissemination process. technological innovation. videogame.

\section{Alfabetización informacional en videojuegos}

Resumen: Este documento presenta una propuesta que busca integrar las áreas de biblioteconomía, tecnología de la información e innovación para presentar una reflexión sobre el gran potencial de innovación existente en las universidades. Se prevé un enfoque sobre la difusión de información como una herramienta educativa para que el proceso de capacitación académica pueda proporcionar un mejor uso de las tecnologías y acciones y acercarlas a las prácticas de enseñanza, investigación y extensión, con respecto al establecimiento y la creación de oportunidades para los estudiantes. para construir conexiones estratégicas entre las prácticas académicas con el mercado laboral. Es un estudio cualitativo con un enfoque hipotético-deductivo, basado en la premisa general del papel y la función de una biblioteca pública universitaria. Se utilizaron análisis bibliográficos y de documentos como medio de investigación para este trabajo. Esta investigación se caracteriza por ser descriptiva, ya que pretende describir y analizar los factores determinantes para la difusión de información sobre innovación y tecnología en el entorno académico. A través de un servicio de referencia centrado en procesos de innovación y mediante una aplicación móvil, busca desarrollar habilidades para la competencia en la información sobre cómo se llevan a cabo las solicitudes de patentes, registros de marcas, solicitudes de derechos de autor y registros de software y demostrar la relevancia de la participación y colaboración. de bibliotecas universitarias en planes de desarrollo institucional. Nuestro objetivo es resaltar la importancia de desarrollar nuevas prácticas educativas que proporcionen un proceso de obtención de experiencia, que acerque la investigación académica a la realidad incluso antes de que un estudiante se haya graduado y les ayude a comprender las diferentes formas de innovación que pueden existir en el campo profesional deseado.

Palabras clave: sistemas de información. proceso de difusión de información. innovación tecnológica. videojuego.

\section{Introdução}

A concepção de um serviço de referência, especificamente para inovação, busca o desenvolvimento do sujeito inovador por meio de uma abordagem sobre as práticas do ensino como propulsoras de inovação e leva para o universo acadêmico a possibilidade de aproximações e conexões com as empresas por meio de contratos de transferência de tecnologias e da realização de ações conjuntas ligadas aos avanços tecnológicos e ao interesse social.

Com as constantes transformações sociais e a crescente globalização, as universidades vêm se reestruturando e construindo espaços que possibilitam a expansão da Universidade para além de seus "muros". As questões de acesso e disseminação da informação implicam 
diretamente na construção/elaboração dos conhecimentos que podem ser transmitidos durante a vida acadêmica. Em contraponto a essas transformações, as competências informacionais para distinguir os conteúdos relevantes não são amplamente difundidas na área acadêmica. Existe a necessidade de métodos e processos de ensino mais atuais que utilizem ferramentas inovadoras, motivacionais e que tenham alcance em toda a comunidade acadêmica. Missa Johnouchi, ao fazer uma análise sobre o Marco de Avaliação Global da Alfabetização Midiática e Informacional, afirma que:

Na condição de pais, cidadãos, líderes, gestores de políticas ou planejadores em campos como educação, comunicação e informação, temos a obrigação e a responsabilidade de garantir que os jovens recebam as ferramentas de acesso à informação para criar e comunicar suas habilidades únicas como formas explícitas de conhecimento. Isso promoveria um futuro mais brilhante para os jovens e ajudaria a aumentar o patrimônio informacional e cultural do mundo em geral. (UNESCO, 2016, p. 11)

Nesse contexto, ressalta-se a importância de se trabalhar as habilidades de uso das Tecnologias de Informação e Comunicação (TIC) de maneira que os indivíduos alcancem resultados concretos para o desenvolvimento de habilidades que possibilitem a construção de processos de inovação.

Propomos um Serviço de Referência para Propriedade Intelectual (SERPI) no qual são realizadas ações para a capacitação dos usuários com relação aos temas de Propriedade Industrial, Intelectual e Empreendedorismo. Longmuir (2014) ressalta a importância da metodologia de aprendizagem ativa para estimular o pensamento crítico e a análise de atividades para solução de problemas por meios interativos de educação.

A apresentação de aulas expositivas em conjunto com um recurso de interação tecnológico/jogo mobile possibilita a construção de competências informacionais relativas aos depósitos de patentes, depósito de direito autoral, registro de marca e registro de programas de computador.

Busca-se com essa ação o fortalecimento do papel das bibliotecas universitárias como mediadoras no processo de aprendizagem, transformando-as em polos de excelência para a recepção, a orientação e a pesquisa de informações para inovação.

\section{Biblioteca universitária}

Tratando-se de ambientes acadêmicos, as bibliotecas universitárias se destacam como um dos locais adequados para realizar ações que estimulem a pesquisa, o senso crítico e a autonomia de seus usuários. Tarapanoff \& Suaiden \& Oliveira $(2002$, p. 2) mencionam que "[...] é preciso levar a informação à sociedade e ensiná-la a usar a informação, tanto no que diz 
respeito ao seu desenvolvimento econômico como para o seu desenvolvimento social e humano propriamente dito.". Destacam ainda cinco estratégias para o desenvolvimento social quando discutem as funções sociais e oportunidades para os profissionais da informação:

1. Provisão do acesso democrático a toda informação publicada;

2. Oferta de oportunidade de aprendizagem constante;

3. Assegurar que os cidadãos possam lidar com computadores e terem acesso aos sistemas que eles precisam;

4. "Animar" a informação para chegar ao indivíduo e conectá-lo à rede;

5. Analisar a informação, inferindo desta novas informações e conhecimento. (p. 2).

Para Mota (1998, p. 111), “Tornou-se necessário reverter às práticas organizacionais existentes para conquistar novas ideias de flexibilidade, mais ajustáveis às mudanças, ambiguidades e contradições do mundo contemporâneo.". Uma das funções sociais das bibliotecas universitárias é dar suporte à formação acadêmica dos indivíduos tornando-os competentes para aplicar os conteúdos e os conhecimentos que a eles são transmitidos.

Faz parte também do universo das bibliotecas universitárias oportunizar o acesso a uma visão mais abrangente sobre o potencial informacional disponível dentro da instituição de ensino. O estabelecimento de um fluxo de informação compatível com as estruturas organizacionais da universidade tem efeito multiplicador e pode ser a força motora do desenvolvimento político, social, cultural e tecnológico. Segundo Cunha $(2000$, p. 87), “[...] à medida que um povo educado e com conhecimento se transforma no elemento-chave da prosperidade, segurança e bem-estar social, a universidade, nessa era de transformações rápidas, destaca-se como uma das mais importantes instituições de nosso tempo.".

De acordo com Suaiden (2008, p. 43), "As bibliotecas precisam ter compromisso com o mundo externo e assumir os seus papéis no que se refere à educação, ensino, treinamento e disseminação dos recursos culturais de um país.". E no que tange às bibliotecas universitárias, Cunha (2000) as define e destaca seu propósito como sendo:

[...] organizações complexas com múltiplas funções e uma série de procedimentos, produtos e serviços que foram desenvolvidos ao longo de décadas. No entanto, o seu propósito fundamental permaneceu o mesmo, isto é: proporcionar acesso ao conhecimento. (p. 7).

O acesso à informação e a capacidade de filtrar e consubstanciar os conteúdos são essenciais para o aumento das capacidades individuais e permitem ultrapassar barreiras na medida em que proporcionam uma nova forma de pensar o processo de constituição e desenvolvimento da sociedade moderna. Para isso, é necessário o desenvolvimento de práticas que estimulem as capacidades inovadoras para adaptar as tecnologias ou aprimorá-las utilizando as infraestruturas de apoio disponíveis nas universidades. 


\section{Serviço de referência e o processo de aprendizagem}

O processo de aquisição de habilidades necessário para a construção de um serviço de referência para inovação passa pela compreensão de como as pessoas aprendem. Segundo Bransford, Brow e Cocking (2007, p. 110), esse processo ocorre por meio de múltiplos contextos. Esses autores consideram que:

Os estudantes são motivados a gastar o tempo necessário para a aprendizagem de assuntos complexos e para solução de problemas que consideram interessantes. As oportunidades para utilizar o conhecimento, para criar produtos e benefícios para os outros, são especialmente estimulantes.

A perspectiva de alfabetização para processos de inovação busca motivar os alunos ao uso das tecnologias digitais como prática pedagógica para o desenvolvimento de conteúdos informacionais relevantes e como forma de desenvolvimento social e econômico. Lalueza, Crespo e Camps (2010 como citado em Costa, Duqueviz e Pedroza, 2015, p. 51) corroboram que:

A tecnologia contribui para orientar o desenvolvimento humano, pois opera na zona de desenvolvimento proximal de cada indivíduo por meio da internalização das habilidades cognitivas requeridas pelos sistemas de ferramentas correspondentes a cada momento histórico. Assim, cada cultura se caracteriza por gerar contextos de atividade mediados por sistemas de ferramentas, os quais promovem práticas que supõem maneiras particulares de pensar e de organizar a mente.

O foco é gerar competência para a busca da informação significativa, para o desenvolvimento de projetos relacionados à inovação em diversas áreas do conhecimento por meio de contextos múltiplos. Paulo Freire diz que "Ensinar não é transferir conhecimentos, mas criar as possibilidades para a sua própria produção ou a sua construção.". (1996, p. 47). Bartel e Hagel, quando falam sobre sistema de aprendizagem baseado em jogos móveis na educação universitária (2014, p. 57), mencionam que:

A motivação de aprendizagem é difícil de promover e envolve a disposição dos estudantes em abordar as capacidades sensoriais, cognitivas e motoras numa situação de aprendizagem pré-definida e coordenar de uma forma adequada para alcançar um objetivo claramente definido. (tradução nossa)

No entanto, os autores destacam que em seus estudos encontraram quatro tópicos que podem aguçar o interesse dos alunos e que devem ser adaptados para o contexto móvel: despertar a curiosidade, promover a independência, adaptar a dificuldade e criar incentivos (Bartel \& Hagel, 2014).

Valente (2014, p. 144) defende que:

A ação educacional consiste justamente em auxiliar o aprendiz, de modo que a construção de conhecimento possa acontecer. Isso implica criar ambientes de aprendizagem onde haja tanto aspectos da transmissão de informação 
quanto de construção, no sentido da significação ou da apropriação de informação. Portanto, a questão fundamental no processo educacional é saber como prover a informação, de modo que ela possa ser interpretada pelo aprendiz que passa a entender quais ações ele deve realizar para que a informação seja convertida em conhecimento.

A criatividade lúdica para oportunizar esse processo de aprendizagem pode ser 0 diferencial para a determinação do sucesso ou fracasso da ação. É preciso buscar uma nova concepção de aprendizagem que seja capaz de aproximar-se das novas tecnologias e dos novos perfis de usuários. Figueiredo, ao falar sobre serviços de referência, menciona que: “[...] o primeiro passo para qualquer programa de instrução é assegurar que o sistema a ser ensinado seja eficiente, de percepção clara e o mais possível auto exploratório.". (1991, p. 112).

A compreensão das competências informacionais surge para desenvolver tais habilidades. De acordo com a International Federation of Library Associations and Institutions (IFLA) (2008), “[...] a competência informacional e o aprendizado ao longo da vida são os faróis da Sociedade da Informação, iluminando os caminhos para o desenvolvimento, a prosperidade e a liberdade.". A IFLA imputa à competência informacional o status de "Direito Humano Básico" e de ser o centro da promoção de inclusão social a todas as nações em um mundo digital. Dudziak (2003, p. 26), ao traduzir o conceito da American Library Association (ALA), destaca que as pessoas competentes em informação "[...] são aquelas que aprenderam a aprender. Elas sabem como aprender, pois sabem como o conhecimento é organizado, como encontrar a informação e como usá-la de modo que outras pessoas aprendam a partir dela.". Belluzzo (2001 como citado em Correa \& Lucas \& Muller, 2018, p. 503) define Competência em Informação como“[...] um processo de interação e internalização de conceitos, atitudes e habilidades específicas que conduzem à compreensão da informação e busca da fluência e capacidades necessárias para a geração de novos conhecimentos e para o uso ético da informação."

Quando Suaiden (2008, p. 48) menciona a ética e o processo de disseminação da informação, ele enfatiza que "[...] o bibliotecário tem a missão de ser o mediador entre livros, documentação, tecnologia e usuário. O papel do bibliotecário não é somente facilitar o acesso à informação, mas, acima de tudo, facilitar o verdadeiro uso.".

Existe a necessidade do reconhecimento, pelos usuários e dirigentes, de que as bibliotecas são espaços de aprendizagem e inovação, e não apenas um simples depósito de livros. Dib \& Oliveira \& Soares (2003, p. 15) defendem que "Estudos de usuários em bibliotecas universitárias revelam que estes, em sua maioria, desconhecem a missão, os objetivos, os 
processos internos e, com exceção dos serviços de consulta, empréstimo e devolução de livros, ignoram os produtos e outros serviços oferecidos pelas bibliotecas.".

Os serviços de referência das bibliotecas universitárias possuem um grande potencial para transformar recursos informacionais em significados e apoiar a construção do conhecimento. Por meio do Serviço de Referência, trabalha-se mais efetivamente para o atendimento das necessidades informacionais dos usuários, facilitando o acesso à informação. Para Jean-Philippe Accart, um serviço de referência "É um lugar físico no qual as pessoas são acolhidas e onde lhes são fornecidas informações que atendam às suas necessidades.". (2012, p. 13). As prestações de serviço em função das necessidades dos usuários, juntamente com a utilização dos novos formatos de comunicação, rompem os limites dos espaços físicos das bibliotecas. O Serviço de Referência é um canal de disseminação dos conteúdos que as bibliotecas têm e que estão à disposição dos usuários.

As necessidades informacionais que surgem no serviço de referência podem ser desde a localização de um livro nas estantes, uma pesquisa de referências/bibliografias, capacitação na utilização de ferramentas, treinamentos em técnicas de recuperação de informação, formas de tratamento dos resultados obtidos ou até o endereço de algum local que esse usuário esteja precisando. O objetivo do serviço de referência é "[...] ser o elo entre a informação e o usuário" (ACCART, 2012, p. 4); é também responder as perguntas dos usuários, ajudá-los a selecionar as obras mais pertinentes para sua pesquisa e com isso promover a personalização dos serviços que são oferecidos pelas bibliotecas. Dentro desse universo, Chaumier e Sutter (2007, como citado por Accart 2012, p. 13) mencionam que, para eles, um serviço de informação "[...] abrange todo mecanismo organizacional e técnico que facilite o acesso à informação ou sua gestão."

A premissa é que as bibliotecas universitárias devem servir de suporte enquanto espaço de aprendizagem e formação acadêmica dos estudantes, bem como à produção da Ciência no que tange as inovações tecnológicas passíveis de transferências.

Jean-Philippe Accart (2012, p. 17), ao falar sobre referência e informação, ressalta o pensamento de Cristiane Volant, que diz que, "Cada vez mais, a real necessidade não é mais por serviços e produtos de informação tradicionais, mas por serviços e produtos elaborados de modo focado, num contexto de utilização particular e num nível de elaboração apropriado".

Strable citado por Figueiredo, já em 1996, destacou que cabe à biblioteca especializada “[...] disseminar informação nova tão rápida e eficientemente quanto possível entre os membros da organização [...]" (p. 78), o que reforça o entendimento de que cabe aos serviços de referência a intermediação e a disseminação das informações relacionadas à inovação que 
estão sendo formuladas pelas universidades como imagem das próprias instituições, inovadoras.

\section{0 jogo da inovação}

A opção pela construção de um jogo mobile está relacionado ao fato de que no Brasil, de acordo com a Pesquisa TIC Domicílios 2014 (CGI.br, 2015), 92\% da população têm acesso a celulares, $76 \%$ fazem uso do celular como forma de acesso à internet e $65 \%$ dos indivíduos da classe " $D$ " fazem uso da internet apenas pelo telefone celular. A pesquisa estima que, em números absolutos, 146,7 milhões de indivíduos possuem telefone móvel. De acordo com o $2^{\circ}$ Censo da Indústria Brasileira de Jogos Digitais, disponibilizado pelo MCTIC (2019a), "Dispositivos móveis, celulares e tablets ainda lideram como plataformas mais utilizadas para a criação de jogos digitais, com $61 \%$ da preferência.". Ainda conforme a pesquisa, nos últimos dois anos foram produzidos 1.718 jogos no país, sendo 874 jogos educativos.

Já em 2016 o MCTIC destacava a importância de "Desenvolver Soluções Inovadoras para Inclusão Produtiva e Social":

A elevação da qualidade da educação passa pela valorização da cultura científica por meio de ações que alcancem todas as camadas sociais, em todo o território nacional. Maneiras mais eficazes de trabalhar a educação científica da população devem ser desenvolvidas a fim de estabelecer expectativas elevadas para todos, motivando os alunos à experimentação e atraindo mais cidadãos para as carreiras de CT\&I. Jovens de talento científico reconhecido devem ter suas práticas inventivas apoiadas antes de atingir a pós-graduação, de forma que o País supere divisões sociais profundas e se destaque em CT\&I. (2019b, p. 68).

Segundo o MCTIC (2019c) "O Brasil é o 4o maior mercado consumidor de games no mundo, com cerca de 66,3 milhões de gamers.". Apenas um evento, o Game XP de 2018, teve um impacto econômico total de R\$53.934.075,13. O MCTIC menciona ainda que, conforme o levantamento realizado pela Fundação Getúlio Vargas (FGV), "Deste montante, $R \$ 36,7$ milhões são de impacto direto, ou seja, gastos com hospedagem, alimentação e transporte. Os $\mathrm{R} \$ 17,2$ milhões restantes são de impacto indireto, ou seja, incidem sobre os fornecedores das atividades atingidas por impacto direto.". (MCTIC, 2019c).

O MCTIC enfatiza que a "[...] área de desenvolvimento também tem apresentado crescimento expressivo, saltando de 50 empresas em 2012, para 240 em 2017, ano em que a receita do setor chegou a US\$ 1,3 bilhão." (2019c).

O desenvolvimento de um jogo eletrônico mobile contribui para a incorporação de um processo de inovação na prática diária dos alunos e é uma mudança na forma de disponibilização das informações se comparado aos modelos que vêm sendo praticados pela instituição ao longo das últimas décadas. Além disso, demonstra também a importância de se pensar e 
prospectar novas práticas pedagógicas que proporcionem um processo de vivência, que aproxime a experiência acadêmica da realidade, antes mesmo da formação do aluno, e o auxilie na compreensão das diferentes formas de inovação que podem existir no exercício profissional almejado. Etzkowitz e Zhou (2017), ao explicarem as fontes da relação existente entre a academia, o governo e as empresas, a Tríplice Hélice, apontam que: A vantagem competitiva da universidade em relação a outras instituições produtoras de conhecimento são os seus alunos. O seu ingresso e graduação regulares traz continuamente novas ideias, em contraste com as unidades de P\&D das empresas e dos laboratórios governamentais, que tendem a se ossificar, sem o "fluxo de capital humano", que é parte intrínseca da universidade. (p. 31)

Destacamos que as universidades são polos de produção de propriedade intelectual e industrial e isso não deve ser deixado de lado durante a formação acadêmica de seus discentes. Quando fala sobre os tipos de softwares, sob o ponto de vista da educação, Valente (1999) afirma que:

[...] um dos objetivos prementes da Educação deve ser o de fazer todo o possível para trazer o sentimento do empowerment de volta à escola e propiciar ao aprendiz a sensação da direção para o futuro. Se pensamos em transformar as escolas, deveríamos lutar para termos ambientes de aprendizagem que podem proporcionar aos alunos a experiência do empowerment. [...] Esse deveria ser o objetivo principal da escola compatível com a sociedade de conhecimento. (p. 82)

Devemos vislumbrar uma nova concepção curricular que permita o desenvolvimento de novas práticas educacionais engajadas com o desenvolvimento tecnológico e social.

De acordo com Huizinga (1993, p.33), um jogo é:

[...] uma atividade ou ocupação voluntária, exercida dentro de certos e determinados limites de tempo e de espaço, segundo regras livremente consentidas, mas absolutamente obrigatórias, dotado de um fim em si mesmo, acompanhado de um sentimento de tensão e de alegria e de uma consciência de ser diferente da vida cotidiana.

Jane Macgonical (2012, posição 258-260) afirma que vê “[...] um futuro no qual os jogos estimulem nosso apetite pelo envolvimento, nos motivando e nos capacitando a estabelecer conexões fortes - e fazendo contribuições maiores - com o mundo à nossa volta." Busca-se com o jogo estimular o engajamento dos alunos através das narrativas, recompensas, por meio de ações interessantes e interativas que envolvam os usuários de forma atrativa e prazerosa.

\section{Materiais e métodos}

Trata-se de uma pesquisa qualitativa com abordagem hipotético-dedutiva por partirmos da premissa geral do papel e da função de uma Biblioteca universitária em uma universidade pública. As bibliotecas universitárias são os centros de informações e devem 
servir de suporte enquanto espaço de aprendizagem e formação acadêmica dos estudantes bem como suporte à produção da Ciência, no que tange às inovações tecnológicas, para investigar a forma de disseminação da informação praticada atualmente.

Quanto aos meios de investigação para este trabalho, foram utilizadas as análises bibliográficas e documentais. A pesquisa bibliográfica foi empregada na definição dos conceitos utilizados no estudo, e a pesquisa documental, na análise dos conteúdos que seriam utilizados.

De acordo com a classificação sugerida por Vergara (2007), quanto aos fins, esta pesquisa caracteriza-se como descritiva, uma vez que se pretende descrever e analisar os fatores determinantes para a disseminação das informações sobre inovação e tecnologia. Ainda segundo a autora, as pesquisas descritivas têm como objetivo a apresentação das características de determinada população ou fenômeno, podendo ainda estabelecer correlações entre variáveis e definir sua natureza.

Para o desenvolvimento do jogo, foi utilizado o motor Construct3, que permite ao projeto um rápido andamento, além de acesso a recursos essenciais para jogos de última geração. Foram abordados tópicos como: criação de fases, tipos de objetos, comportamentos, eventos, animação e propagandas institucionais que podem ser visualizadas ao final de cada fase.

\section{Prospecção para inovação}

Para identificar e avaliar a proposta, buscou-se uma melhor compreensão do ambiente no qual o jogo mobile está inserido, usando técnicas de prospecção tecnológica. Conforme Antunes et al. (2018, p. 29), "A prospecção tecnológica usa diferentes atividades e/ou métodos de captação, tratamento e análise de informações para subsidiar os processos de tomada de decisão.". A intenção é trazer à luz um conjunto de indicadores que, ao serem utilizados, possam mapear a tecnologia e as condições para o seu desenvolvimento e traçar os caminhos mercadológicos para que ocorra o processo de inovação.

Cabe salientar que o jogo proposto é passível de registro de programa de computador junto ao Instituto Nacional Propriedade Industrial - INPI. O Guia Básico de Programa de Computador (INPI, 2019a) menciona que, depois de concedido o registro, a validade do direito é de "[...] 50 anos a partir da sua criação ou de 1ำ de janeiro do ano subsequente à sua publicação. A proteção não é territorial, isto é, sua abrangência é internacional, compreendendo os 175 países signatários da Convenção de Berna (1886).".

Para estabelecer um cenário sobre os tipos de instituições que efetuam os depósitos de programa de computadores, foram coletados dados junto ao INPI, no Boletim Mensal de 
Indicadores Industriais, que destaca as seguintes instituições entre os 2.498 depósitos realizados de janeiro a outubro de 2019 por residentes no Brasil:

Instituições de ensino e pesquisa e governo 899 pedidos; Empresas de médio e grande porte 557 pedidos; Pessoas físicas 577 pedidos; MEI, microempresa e EPP 347 pedidos; Associações e sociedades de intuito não econômico 111 pedidos; Cooperativas 7 pedidos. (INPI, 2019b).

Para análise de prospecção na base de dados da Capes, foi identificado que os termos Mobile Game-Based Learning AND Education apresentaram maior precisão com relação à proposta do jogo. Foram utilizados para a pesquisa apenas os resultados dos últimos 20 anos por considerarmos que estudos anteriores não versam sobre aplicativos móveis de acordo com o conceito abordado na presente pesquisa. Foi possível identificar 2.588 artigos relacionados ao tema.

O INPI (2019b, p. 9) informa que, com relação aos depósitos de registro de computadores, os depósitos acumulados entre novembro de 2019 até outubro de 2019 têm “[...] uma trajetória de alta a partir de abril/2018 com os depósitos alcançaram 2.976 indicando variação positiva de $25,8 \%$ sobre o período anterior (2.365).".

Desta forma, podemos inferir que a relação entre artigos e registro de computadores se apresenta de forma pouco linear e é um indicativo da conveniência de se criar uma ferramenta/jogo de divulgação sobre as etapas e os processos para a efetivação dos registros e depósitos que resultarão em serviços/produtos de inovações junto à UnB.

\section{Considerações finais}

À medida que atrairmos e engajarmos um público contemporâneo, conseguiremos servir de apoio para alavancar o desenvolvimento dos ecossistemas de inovação das universidades e o alcance das metas e dos objetivos estratégicos traçados pelos planos de desenvolvimento institucionais. A dimensão educacional proposta pode ser definida pelo estímulo às atividades inovadoras e à aquisição de competências necessárias para as etapas técnicas que garantam aos discentes o gozo de forma plena dos direitos intelectuais e industriais. O serviço de referência proposto e o jogo colocam a biblioteca como parte do processo de inovação que vem acontecendo nas universidades e faz transparecer sua dimensão educacional.

O acréscimo da tecnologia nas rotinas diárias das bibliotecas universitárias pode transformar o comportamento dos usuários com relação à sua visão sobre o que é um centro 
de informação e as possibilidades de desenvolvimento de projetos de pesquisa para inovação apoiados pelas equipes técnicas.

Temos que refletir sobre a necessidade de aprimoramento do uso de objetos de aprendizagem na produção de modelos educacionais que estimulem o raciocínio, o planejamento e o processamento efetivo das informações que são disponibilizadas pelas universidades, a fim de aumentar a escala de uso das informações e reduzir o custo da aprendizagem com a geração de ativos tangíveis como estratégia para o desenvolvimento tecnológico. Destacamos que o jogo não pretende substituir qualquer outra forma de instrução sobre inovação, pois acreditamos que esse recurso tecnológico deve ser considerado com um complemento às atividades que hoje são realizadas.

Considerando o que foi exposto, podemos ressignificar as bibliotecas universitárias enquanto espaço de aprendizagem, como um ambiente potencialmente positivo que proporciona interações sociais e contribui com o desenvolvimento de estratégias; que criam condições de trazer uma experiência que vai além do acesso, integrando significativamente recursos tecnológicos e midiáticos para que os usuários possam dominar operações e funcionalidades dos processos tecnológicos que integram seus currículos durante sua formação acadêmica.

O estabelecimento de um fluxo de informação compatível com as estruturas organizacionais da universidade tem efeito multiplicador e pode ser a força motora do desenvolvimento político, social, cultural e tecnológico.

\section{Referências}

ACCART, Jean-Philippe. Serviço de Referência: do presencial ao virtual. Brasília: Briquet de Lemos, 2012.

ANTUNES, Adelaine Maria de Souza, et al. Métodos de Prospecção Tecnológica, Inteligência Competitiva e Foresight: principais conceitos e técnicas. In: RIBEIRO, Núbia Moura. (2018). Prospecção Tecnológica. Salvador: I FBA. 2018. v.1. Disponível em: http://www.profnit.org.br/wp-content/uploads/2018/08/PROFNIT-Serie-ProspeccaoTecnologica-Volume-1-1.pdf Acessado em: 23 agosto, 2019.

BARTEL, A.; HAGEL, G. Engaging Students with a Mobile Game-Based Learning System in University Education. International Journal of Interactive Mobile Technologies iJIM, v. 8, n. 4, p. 56-60, 2014. Disponível em: http://online-journals.org/index.php/ijim/article/viewFile/3991/3298 Acessado em: 2 junho, 2019.

BRANSFORD, John. D., BROWN, Ann. L.; COCKING, Rodney. R. Como as pessoas aprendem: cérebro, mente, experiências e escola. São Paulo: Senac, 2007.

BRASIL. Ministério da Ciência, Tecnologia, Inovação e Comunicação (MCTIC). Notícias Gerais: Mercado de jogos eletrônicos cresce em todas as regiões do País, aponta $2^{\circ}$ Censo de Games. 
2019a Disponível em: http://cultura.gov.br/mercado-de-jogos-eletronicos-cresce-em-todas-asregioes-do-pais-aponta-2o-censo-de-games/Acessado em: 13 outubro, 2019.

BRASIL. Ministério da Ciência, Tecnologia, Inovação e Comunicação (MCTIC). Estratégia Nacional de Ciência, Tecnologia e Inovação 2016/2022: Ciência, Tecnologia e Inovação para o Desenvolvimento Econômico e Social. Brasília, 2016. Disponível em: https://portal.insa.gov.br/images/documentos-oficiais/ENCTI-MCTIC-2016-2022.pdf Acessado em: 30 novembro, 2019.

BRASIL. Ministério da Ciência, Tecnologia, Inovação e Comunicação (MCTIC). Notícias Destaques: Game XP gera impacto econômico de RS 53,9 milhões para o Brasil. 2019c Disponível em: http://cultura.gov.br/game-xp-gera-impacto-economico-de-r-53-9-milhoespara-o-brasil/ Acessado em: 12 outubro, 2019.

COMITÊ GESTOR DA INTERNET NO BRASIL - CGI.br. Pesquisa sobre o uso das tecnologias de informação e comunicação nos domicílios brasileiros: TIC Domicílios 2014. São Paulo: CGI. Br, 2015. Disponível em:

http://cetic.br/media/docs/publicacoes/2/TIC Domicilios 2014 livro eletronico.pdf Acessado em: 10 setembro, 2019.

CORREA, Elisa Cristina Delfini; LUCAS, Elaine Rosangela Oliveira; MULLER, Viviane Formiguieri. Conexão entre competência em informação e as disciplinas fontes de informação e serviço de referência: um mapa conceitual. RDBCl: Revista Digital de Biblioteconomia e Ciência da Informação, Campinas, v. 16, n. 2, p. 501-521, 2018. Disponível em: https://periodicos.sbu.unicamp.br/ojs/index.php/rdbci/article/view/8649760 Acessado em: 2 março, 2019.

COSTA, Sandra Regina Santana; DUQUEVIZ, Barbara Cristina; PEDROZA, Regina Lúcia Sucupira. Tecnologias Digitais como instrumentos mediadores da aprendizagem dos nativos digitais. Psicologia Escolar e Educacional, v. 19, n. 3, p. 603-610, 2015. Disponível em: https://dx.doi.org/10.1590/2175-3539/2015/0193912 Acessado em: 1 maio 2019.

CUNHA, Murilo Bastos da. Construindo o futuro: a biblioteca universitária brasileira em 2010. Ciência da Informação, v. 29, n. 1, p. 71-89, 2000. Disponível em: https://dx.doi.org/10.1590/S0100-19652000000100008 Acessado em: 13 maio, 2019.

DIB, Simone Faury; OLIVEIRA, V. P.; Soares, M.F. Um Novo Modelo de Negócio para Bibliotecas. 2003. Centro de Referência em Inteligência Empresarial. UFRJ /COPPE. Disponível em: http://www.crie.ufri.br/centro-de-estudos/0/projetos-mbkm/20 Acessado em: 4 maio 2019.

DUDZIAK, Elisabeth Adriana. Information literacy: princípios, filosofia e prática. Ciência da Informação, v. 32, n. 1, p. 23-35, 2003. Disponível em: https://dx.doi.org/10.1590/S010019652003000100003 Acessado em: 20 nov. 2019.

ETZKOWITZ, Henry; ZHOU, Chunyan. Hélice Tríplice: inovação e empreendedorismo universidade-indústria-governo. Estudos Avançados, v. 31, n. 90, p. 23-48, 2017. Disponível em: https://dx.doi.org/10.1590/s0103-40142017.3190003 Acessado em: 25 maio, 2019. 
FIGUEIREDO, Nice Menezes de. Metodologias Para a Promoção do Uso da Informação. São Paulo: Nobel: Associação Paulista de Bibliotecários, 1991.

FIGUEIREDO, Nice Menezes de. Textos avançados em referência \& Informação. São Paulo: Polis, 1996.

FREIRE, Paulo. Pedagogia da Autonomia: Saberes necessários à prática educativa. São Paulo: Paz e Terra, 1996.

HUIZINGA, Johan. Homo Ludens. 4. ed. São Paulo: Perspectiva, 1993.

INTERNATIONAL FEDERATION OF LIBRARY ASSOCIATIONS ( IFLA). Declaração de Alexandria sobre Competência Informacional e Aprendizado ao longo da vida. 2008. Disponível em: https://www.ifla.org/files/assets/wsis/Documents/beaconinfsoc-pt.pdf Acessado em: 28 abril, 2019.

INSTITUTO NACIONAL DE PROPRIEDADE INDUSTRIAL (INPI). Boletim Mensal de Propriedade Industrial. Boletim mensal de Propriedade Industrial, Rio de Janeiro, v. 3, n. 11, p. 1-20, nov. 2018. Disponível em:

http://www.inpi.gov.br/sobre/estatisticas/arquivos/publicacoes/boletim nov 2018.pdf Acessado em: 10 nov. 2019.

INSTITUTO NACIONAL DE PROPRIEDADE INDUSTRIAL (INPI). O Guia Básico de Programa de Computador. 2019a. Disponível em: http://www.inpi.gov.br/menu-servicos/programa-decomputador Acessado em: 02 junho, 2019.

LONGMUIR, Kenneth J. Interactive computer-assisted instruction in acid-base physiology for mobile computer platforms. Advances in Physiology Education, v. 38, n. 1, p. 34-41, 2014. Disponível em: https://www.physiology.org/doi/full/10.1152/advan.00083.2013 Acessado em: 8 maio, 2019.

MACGONICAL, Jane. A realidade em jogo: Porque os games nos tornam melhor e como eles podem mudar o mundo. Rio de Janeiro: Bestseller, 2017. (Recurso digital Kindle)

MOTTA, Paulo Roberto. Gestão contemporânea: a ciência e a arte de ser dirigente. 10 ed. Rio de Janeiro: Record, 1999.

SUAIDEN, Emir José. Ética e o Impacto Social na Biblioteca Pública. In: SUAIDEN, Emir José; OLIVEIRA, Cecília Leite. Formação de Leitores e Construção da Cidadania: memória e presença do PROLER. Rio de Janeiro: Fundação Biblioteca Nacional, 2008.

TARAPANOFF, Kira.; SUAIDEN, Emir José.; OLIVEIRA, Cecília Leite. Funções sociais e oportunidades para profissionais da informação. DataGramaZero, Rio de Janeiro, v. 3, n. 5, p. 1-11, $2002 . \quad$ Disponível em: https://ridi.ibict.br/bitstream/123456789/256/1/CECILIADTZ2002.pdf Acessado em: 04 maio, 2019.

UNESCO. Marco de Avaliação Global da Alfabetização Midiática e Informacional (AMI): disposição e competências do país. Brasília: UNESCO, Cetic.br, 2016. Disponível em: http://unesdoc.unesco.org/images/0024/002463/246398POR.pdf Acessado em: 14 maio, 2019. 
VALENTE, José Armando. Análise dos Diferentes Tipos de Software Usados na Educação. In: VALENTE, José Armando (Org). O computador na sociedade do conhecimento. Campinas: Unicamp, 1999.

VALENTE, José Armando. A Comunicação e a Educação baseada no uso das Tecnologias Digitais de Informação e Comunicação. Revista UNIFESO - Humanas e Sociais, v. 1, n. 1, p. 141-166, 2014. Disponível em: http://www.revistasunifeso.filoinfo.net/index.php/revistaunifesohumanasesociais/article/vie $\underline{\mathrm{w} / 17 / 24}$ Acessado em: 20 novembro, 2019.

VERGARA, Sylvia Constant. (2007). Projetos e Relatórios de Pesquisa em Administração. São Paulo, SP: Atlas. 